\title{
Custo-benefício da secagem de café em diferentes tipos de terreiro
}

Oswaldo Lahmann Santos ${ }^{1}$

Carlos Henrique Rodrigues Reinato ${ }^{2}$

Juliano Donizete Junqueira ${ }^{3}$

Emerson Loiola Franco 4

Caio Welber Alves Souza 5

Aydison Neves Rezende ${ }^{6}$

\section{Resumo}

Neste trabalho objetivou-se comparar o custo de construção entre o terreiro de lama de cimento e outros diferentes tipos de terreiros de café, bem como a interferência desses terreiros na qualidade sensorial e alterações físico-químicas do café. 0 delineamento experimental consistiu em um delineamento inteiramente casualizado (DIC), com os tratamentos dispostos em fatorial. Foram utilizadas três repetições para cada tratamento. Após a secagem, as unidades experimentais foram beneficiadas e submetidas às análises. Para avaliação da composição química e física, foram realizados os testes de análise de condutividade elétrica e análise sensorial. Pelos resultados, verificou-se que o terreiro de lama de cimento se apresentou como uma excelente alternativa para a secagem do café, tanto do ponto de vista econômico quanto do ponto de vista qualitativo.

Palavras-chave: Pós-colheita. Pavimentação. Influência. Processamento. Cafeicultura.

\section{Introdução}

A despeito das mudanças experimentadas pela cafeicultura mundial ao longo das últimas quatro décadas, o Brasil manteve-se como maior produtor e exportador de café do mundo. Nesse período, surgiram novos grandes produtores mundiais, foram introduzidas novas tecnologias e a qualidade do café ganhou maior importância como fator de diferenciação do produto (SIQUEIRA, 2005).

Estima-se que no Brasil 70 \% da produção de café seja proveniente de pequenas e médias propriedades rurais, segundo Camargo e Oliveira (2010). Na pequena propriedade agrícola, os trabalhos são executados, na grande maioria, por mão de obra familiar. Do mesmo modo que o café é uma cultura altamente dependente de mão de obra, a qual representa cerca de $50 \%$ do seu custo de produção, ele é também um agente de equilíbrio social, pois democratiza, distribui e interioriza a renda.

No entanto, os pequenos cafeicultores têm sido penalizados com baixa remuneração do seu negócio, principalmente por apresentarem infraestrutura insuficiente para o adequado processamento dos grãos, produzindo frequentemente cafés de qualidade inferior, não usufruindo dos benefícios das

1 Instituto Federal de Educação, Ciência e Tecnologia do Sul de Minas Gerais - Campus Machado, discente, Machado (MG), $37750-000$. oswaldolahmannagro@gmail.com.

2 InstitutoFederaldeEducação, CiênciaeTecnologiadoSuldeMinasGerais-Campus Machado, docente.carlos.reinato@ifsuldeminas.edu.br.

3 Instituto Federal de Educação, Ciência e Tecnologia do Sul de Minas Gerais -Campus Machado, discente. julianodjunqueira@gmail.com.

4 Instituto Federal de Educação, Ciência e Tecnologia do Sul de Minas Gerais - Campus Machado, discente. emersonlf.agro@gmail.com.

5 Instituto Federal deEducação, Ciência eTecnologiadoSuldeMinas Gerais-Campus Machado, discente.caiowelbersouza94@hotmail.com.

6 Instituto Federal de Educação, Ciência e Tecnologia do Sul de Minas Gerais - Campus Machado, servidor. aydisonrezende@hotmail.com. 
novas tendências do mercado. Dessa forma, tecnologias adequadas à atividade do pequeno produtor que garantam qualidade e segurança alimentar adquiriram grande importância.

Considerando toda a cadeia produtiva do café, o processamento, a secagem e o armazenamento mal conduzido são as principais etapas que reduzem a qualidade do café e aumentam o risco sanitário.

Os frutos do café geralmente são colhidos com teor de água entre 30 e 65 \% Base úmida (bu), dependendo do seu estado de maturação, portanto, sujeitos a condições favoráveis e à rápida deterioração. Assim, antes de ser armazenado o café deverá necessariamente ser secado (BORÉM, 2008).

A secagem pode ser definida como processo simultâneo de transferência de energia e massa entre o produto e o ar de secagem, consistindo na remoção do excesso de água contida no grão por meio da evaporação, geralmente causada por convecção forçada de ar aquecido, de modo a permitir a manutenção de sua qualidade durante o armazenamento (HALL, 1980).

No Brasil, a secagem do café é feita em terreiros ou em secadores mecânicos ou pela combinação desses dois. No processo de secagem em terreiro, o café é secado pela ação dos raios solares.

Com o mercado atual que prioriza cada vez mais a qualidade do café, torna-se necessário o desenvolvimento de práticas e técnicas inovadoras que tragam credibilidade a essas ideias. 0 aprimoramento dos dois métodos de secagem, após análise dos diversos modelos de terreiros empregados e utilizados pelos produtores, é uma forma de contribuir para essa inovação.

Considerando as diversas etapas da pós-colheita (processamento, secagem, armazenamento, beneficiamento e transporte), a secagem é a etapa de maior relevância, tanto do ponto de vista de consumo de energia e formação dos custos de processamento quanto do ponto de vista da preservação da qualidade (BORÉM et al., 2008).

No processo de secagem em terreiros, as estruturas usadas em suas construções podem ser encontradas em diversos tipos de materiais como lama asfáltica, lama de concreto, terra, concreto, suspenso.

A interferência do tipo de pavimentação na qualidade final do produto e do seu custo de implantação são os principais questionamentos realizados pelos produtores da nossa região.

Desta maneira objetivou-se com a realização deste trabalho verificar o efeito deletério do terreiro de terra sobre os valores médios de condutividade elétrica em todas as formas de preparo e secagem do café, além de comparar a qualidade da bebida e custo de implantação de diferentes tipos de terreiro.

\section{Referencial teórico}

Atualmente nota-se uma variação no comportamento dos produtores de café em relação à qualidade do seu produto, a qual vem sendo motivo de acréscimo no valor desta mercadoria de destaque no agronegócio brasileiro. Isso vem gerando maior dedicação aos processos de pós-colheita, impactando diretamente a manutenção da qualidade do café desde quando este chega da lavoura.

0 processamento do café pode ser realizado de formas distintas: mantendo-se o fruto intacto, ou seja, o fruto é processado em sua forma integral, comumente denominado de café natural; removendo-se apenas a casca e parte da mucilagem, denominado cereja descascado (CD); removendo-se a casca e a mucilagem mecanicamente (desmucilado); removendo-se a casca mecanicamente e a mucilagem por meio de fermentação (despolpado) (REINATO, 2006). Como a casca e a mucilagem são substratos propícios ao desenvolvimento de micro-organismos, sua remoção pode evitar a ocorrência de fermentações prejudiciais à qualidade final do produto (BARTHOLO; GUIMARÃES, 1997). 
Cortez (1997) e Brando (1999) relatam que as principais vantagens do descascamento são a eliminação dos frutos verdes, a diminuição dos custos de beneficiamento e a diminuição da porcentagem de bebidas fermentadas. Além disso, esse sistema de processamento tem a vantagem de diminuir consideravelmente a área de terreiro e o tempo necessário para secagem (SILVA, 1998).

Leite e Carvalho (1996) e Quintero (2000), ao avaliarem diferentes tipos de colheita e processamento do café, observaram que o descascamento melhorou a qualidade do café. Brando (1999) relata que o café cereja descascado pode ser considerado um método intermediário entre o processamento natural e o despolpado, pois ele mantém as características típicas do corpo, aroma e doçura dos cafés brasileiros.

Geralmente os cafés naturais possuem maior corpo enquanto os cafés despolpados possuem aroma mais acentuado e leve e prazerosa acidez. Frequentemente encontram-se relatos que descrevem cafés produzidos pela via seca com qualidade comparativamente distinta dos cafés produzidos pela via úmida (WILBRAUX, 1963; PUERTA-QUINTERO, 1996; VILELA, 2002).

Malta et al. (2003) verificaram que teores médios de açúcares totais têm maiores concentrações nos cafés cereja desmucilado e boia. O café cereja possui maior teor de açúcares redutores, justificado pelo fato de que, quando o fruto de café é seco com polpa e mucilagem, rica em açúcares, podem ocorrer translocações desses componentes químicos para o interior do grão (PEREIRA, 2002; VILELLA, 2002).

Existem vários fatores que influenciam a qualidade final do café: características edafoclimáticas, cultivares, condução e manejo da lavoura, colheita, tipo de processamento, secagem e armazenamento (CARVALHO; CHALFOUN, 1985; CARVALHO et al., 1994).

Além do processamento, a secagem é uma das principais etapas que influenciam a qualidade, principalmente se for mal conduzida (LACERDA FILHO, 1989; VILELA, 1997; SILVA et al., 1998). A qualidade do café natural, se comparada à do café descascado, é comprometida em maior intensidade quando as condições ambientais e de manejo durante a secagem em terreiros são desfavoráveis, especialmente em terreiros não pavimentados (REINATO et al., 2012).

Os terreiros para secagem de café são construídos de diversos materiais, sendo os mais usados representados pelos terreiros de chão batido, tijolo, concreto, asfalto, lama asfáltica e leito suspenso. Vários trabalhos vêm sendo realizados com o objetivo de estudar a interferência da pavimentação na qualidade sensorial do café (SANTOS et al., 1971; SANTIAGO; TEIXEIRA, 1977; HASHIZUME et al., 1985; LACERDA FILHO, 1986; VIANA et al., 2002; BORÉM et al., 2003; REINATO et al., 2005).

SILVA et al. (2008) e Chagas e Malta (2008), verificando o efeito de diferentes formas de preparo e tipos de terreiro de secagem na composição química do café, constataram a existência de diferenças na composição química dos grãos de café em função tanto da forma de preparo do café quanto do tipo de terreiro de secagem utilizado, assim como a interação desses dois fatores em todas as variáveis qualitativas analisadas. Assim, sementes que sofrem danos estruturais na membrana liberam grande quantidade de eletrólitos na solução, resultando em alto valor de condutividade elétrica (BEDFORD, 1974; WOODSTOCK, 1973). Prete (1992) verificou uma relação inversa entre a qualidade da bebida e a condutividade elétrica e a lixiviação de potássio de exsudatos de grãos crus.

\section{Material e métodos}

A pesquisa foi realizada no Instituto Federal de Educação, Ciência e Tecnologia do Sul de Minas Gerais - Campus Machado (21 42' S; 45 53' W;), onde foi obtido o material necessário para o desenvolvimento da pesquisa. 
Os terreiros experimentais com área de $50 \mathrm{~m}^{2}$ foram construídos no setor de pós-colheita de café da seguinte forma:

O local todo passou pelos mesmos processos de limpeza, melhoria da estrutura física do solo, revolvimento do solo, irrigação, compactação e nivelamento. Em seguida, demarcaram-se as áreas de cada terreiro e realizou-se o nivelamento mais "justo". Os materiais usados para a construção dos terreiros foram:

1. Concreto: Foram usados para a construção dos $50 \mathrm{~m}^{2}$ de terreiro 15 sacos de cimento, $1.687,5$ litros de areia e 1.012,5 litros de brita. Para cada traço, foram utilizados 1 saco de cimento, 112,5 litros de areia e 67,5 litros de brita, que foram misturados na betoneira. Cada traço rendeu em torno de 3 a $4 \mathrm{~m}^{2}$. Este tipo de terreiro tem espessura de 10 centímetros e é mais áspero.

2. Lama de cimento: Foram usados para a construção dos $50 \mathrm{~m}^{2}$ de terreiro 6 sacos de cimento, 540 litros de areia e 405 litros de pó de brita. Para cada traço, foram utilizados 1 saco de cimento, 120 litros de areia e 90 litros de pó de brita que foram misturados na betoneira. Cada traço rendeu em torno de $11 \mathrm{~m}^{2}$, e 1,5 saco de cimento foi utilizado para queimar a pavimentação. Este terreiro tem espessura de 5 centímetros e é mais liso.

3. Lama asfáltica: Foram usados para a construção dos $50 \mathrm{~m}^{2}$ de terreiro 12 quilos de cimento, 120 litros de areia, 600 litros de pó brita, 156 litros de água e 144 litros de rápido e liso (RL). Para cada traço, foram utilizados 1 quilo de cimento, 13 litros de água, 10 litros de areia, 50 litros de brita e 12 litros de RL que foram misturados na betoneira. Cada traço rendeu em torno de 4 a $5 \mathrm{~m}^{2}$. Este terreiro tem espessura de 0,5 a 1 centímetro e é mais liso do que o terreiro de concreto e mais áspero do que o Lama de Cimento.

4. Leito suspenso: Foram usados 14 moirões de diâmetro $12 \mathrm{~cm}, 8$ moirões de diâmetro 20 cm, 60 quilos de cimento, 90 litros de pedra, 126 litros de areia, 400 metros de fio liso, 14 unidades de catracas e $50 \mathrm{~m}^{2}$ de sombrite. Neste terreiro o café fica suspenso e o sombrite está a 1 metro de altura do chão.

5. Terra: Foram feitos neste terreiro apenas limpeza, terraplanagem, nivelamento e compactação.

O café foi colhido no ano de 2013, a cultivar usada foi o catuaí amarelo IAC 62 localizado nas coordenadas geográficas $21^{\circ} 42^{\prime} 16,2^{\prime \prime} S$; 4552'48,85"O, com idade de 4 anos e uma gleba de 1,0 hectare, espaçamento de 3,5 x 0,8 m; para o desenvolvimento deste trabalho, foram obtidos 3.000 litros pelo método de derriça manual no pano, retirando o café de roça $(R)$. A partir desta prática, o restante foi encaminhado para o processo de pós-colheita, em que passou pelas seguintes etapas: moega de recepção, abanador, lavador, separador e descascador. Após as etapas, foram obtidos os cafés cereja descascado (CD) e boia (B).

Os cafés roça, cereja descascado e boia foram levados para secar nos seguintes tipos de terreiro: lama asfáltica, lama de cimento, leito suspenso, terra e concreto. Quando colocados os grãos em seus respectivos "tratamentos", retiraram-se amostras de café para acompanhamento dos teores de água do grão.

A partir do tipo de café, definiu-se a espessura das leiras, que até atingir a meia seca foram de $3 \mathrm{~cm}$ com revolvimento constante. Após essa etapa, as leiras tiveram uma espessura maior, em torno de $15 \mathrm{~cm}$ de altura para evitar a formação do defeito preto-verde que ocorre pela elevação da temperatura (BORÉM et al., 2008). 
O delineamento experimental foi constituído em um delineamento inteiramente casualizado (DIC), em forma fatorial $5 \times 3$, pelo qual foi possível obter a comparação dos cinco tipos de terreiro (terra, lama de cimento, lama asfáltica, concreto e leito suspenso), com os três tipos de processo de café (roça, boia e cereja descascado), com três repetições, totalizando 45 parcelas.

Os respectivos tratamentos receberam as seguintes siglas:

$\mathrm{T} 1$ - Terreiro de terra $+\mathrm{CD}$

T2 - Terreiro de terra $+\mathrm{B}$

$\mathrm{T} 3$ - Terreiro de terra $+\mathrm{R}$

T4 - Terreiro de concreto $+C D$

T5 - Terreiro de concreto $+\mathrm{B}$

T6 - Terreiro de concreto $+\mathrm{R}$

T7 - Terreiro de lama de Cimento $+C D$

T8 - Terreiro de lama de Cimento + B

T9 - Terreiro de lama de Cimento + $\mathrm{R}$

T10 - Terreiro de lama de Asfáltica + CD

T11 - Terreiro de lama de Asfáltica + B

T12 - Terreiro de lama de Asfáltica + R

T13 - Terreiro suspenso + CD

T14 - Terreiro suspenso + B

$\mathrm{T} 15$ - Terreiro suspenso $+\mathrm{R}$

Todos tiveram o mesmo manejo de secagem.

O processo da secagem foi interrompido quando os grãos atingiram $11 \%$ de base úmida (b.u); foram retiradas amostras de cada parcela, que foram levadas para o beneficiamento e submetidas a análises físico-químicas e de qualidade sensoriais.

Teor de umidade: Retirou-se uma amostra de cada parcela para o teor de umidade inicial, a qual foi levada para o laboratório. Foi realizada a medição da massa fresca do café no laboratório, a qual resultou em torno de 5 gramas, e, após, foi colocada em porcelana de alumínio e submetida à secagem em estufa de esterilização a $105^{\circ} \mathrm{C}$ durante $24 \mathrm{~h}$. Essas amostras foram retiradas da estufa e colocadas no dessecador por 40 minutos para esfriar; após, foi efetuada a pesagem da massa seca do café. Esta etapa foi repetida de $24 \mathrm{em} 24 \mathrm{~h}$ por todo ciclo de secagem até as parcelas atingirem 11 \% (b.u).

Condutividade elétrica: A condutividade elétrica dos grãos crus foi determinada utilizando três repetições de 50 grãos de cada amostra, os quais foram pesados (precisão de 0,001g) e imersos em $75 \mathrm{~mL}$ de água deionizada no interior de copos plásticos de $180 \mathrm{~mL}$ de capacidade. A seguir, os recipientes foram colocados em uma BOD (Biochemicaloxygendemand) regulada em $25{ }^{\circ} \mathrm{C}$, por $4 \mathrm{~h}$, seguidos pela leitura da condutividade elétrica da solução em condutivímetro.

Classificação pela prova de xícara: A prova de xícara foi realizada por 3 provadores qualificados pertencentes a instituições parceiras do Instituto Federal de Educação, Ciência e Tecnologia do Sul de Minas Gerais, Campus Machado. Cada profissional analisou as 45 parcelas experimentais de acordo com a Instrução Normativa no 8 de 2003 (BRASIL, 2003).

Análise estatística: 0 método utilizado para avaliação do experimento deu-se por meio do programa estatístico Sisvar (FERREIRA, 2000).

\section{Resultados e discussão}

Na Tabela 1 estão representados os custos de cada terreiro. 
Tabela 1. Valores reais da construção dos terreiros de $50 \mathrm{~m}^{2}$. Machado, 2014, IFSULDEMINAS Campus Machado.

\begin{tabular}{lccccc}
\hline \multicolumn{1}{c}{ Operações } & Terreiro de terra & $\begin{array}{c}\text { Terreiro de } \\
\text { concreto }\end{array}$ & $\begin{array}{c}\text { Terreiro lama de } \\
\text { cimento }\end{array}$ & $\begin{array}{c}\text { Terreiro lama } \\
\text { asfáltica }\end{array}$ & $\begin{array}{c}\text { Terreiro leito } \\
\text { suspenso }\end{array}$ \\
\hline $\begin{array}{l}\text { Custo mão de } \\
\text { obra }\end{array}$ & $\mathrm{R} \$ 47,00$ & $\mathrm{R} \$ 328,00$ & $\mathrm{R} \$ 327,00$ & $\mathrm{R} \$ 327,00$ & $\mathrm{R} \$ 248,00$ \\
\hline $\begin{array}{l}\text { Custo } \\
\text { terraplanagem }\end{array}$ & $\mathrm{R} \$ 88,00$ & $\mathrm{R} \$ 98,88$ & $\mathrm{R} \$ 72,16$ & $\mathrm{R} \$ 72,16$ & $\mathrm{R} \$ 47,00$ \\
\hline Custo material & $\mathrm{R} \$ 0,00$ & $\mathrm{R} \$ 688,13$ & $\mathrm{R} \$ 183,45$ & $\mathrm{R} \$ 302,00$ & $\mathrm{R} \$ 1.632,19$ \\
\hline Custo total & $\mathrm{R} \$ 135,00$ & $\mathrm{R} \$ 1.115,01$ & $\mathrm{R} \$ 582,61$ & $\mathrm{R} \$ 701,16$ & $\mathrm{R} \$ 1.927,19$ \\
\hline Custo/m ${ }^{2}$ & $\mathrm{R} \$ 2,70$ & $\mathrm{R} \$ 22,30$ & $\mathrm{R} \$ 11,65$ & $\mathrm{R} \$ 14,02$ & $\mathrm{R} \$ 38,54$ \\
\hline
\end{tabular}

Fonte: Santos, O. L. (2014)

Observa- se na Tabela 1 que o terreiro com custo de construção mais elevado foi o de leito suspenso, sendo que o que mais contribuiu para isso foi o custo dos materiais (moirão, arame galvanizado, tela e cabos de aço); o de segundo maior custo foi o terreiro de concreto, por necessitar de mais recursos como brita, areia e cimento, pois sua espessura é de aproximadamente $10 \mathrm{~cm}$.

O pavimento mais barato foi o de terra por necessitar apenas da terraplanagem e de compactação, no entanto, não foi comparado aos demais por não ser considerado um pavimento recomendado, pois segundo Reinato (2006) este tipo de pavimentação oferece grandes riscos sanitários ao produto final. Portanto, exceto pelo terreiro de terra, o de lama de cimento foi o que apresentou o menor custo, sendo $50 \%$ menor que o custo do terreiro de concreto. Desta maneira, o terreiro de lama de cimento se apresenta como uma ótima opção do ponto de vista econômico para substituição do terreiro de terra.

Observa-se também que o terreiro de lama de cimento teve um custo $25 \%$ menor que o de lama de asfalto. Muitas vezes o produtor tem dificuldades de conseguir a emulsão asfáltica no mercado, portanto, do ponto de vista econômico, o terreiro de lama de cimento se coloca como mais uma alternativa de pavimentação, superando o terreiro de lama asfáltica.

Tabela 2. Valores médios de condutividade elétrica (C.E) $\left(\mu \mathrm{S} . \mathrm{cm}^{-1} \cdot \mathrm{g}^{-1}\right)$ na secagem em diferentes tipos de terreiros e processamento de café. Machado, 2014, IFSULDEMINAS Campus Machado.

\begin{tabular}{lccccc}
\hline Tipo de processamento & $\begin{array}{c}\text { Terreiro de } \\
\text { concreto }\end{array}$ & $\begin{array}{c}\text { Terreiro lama } \\
\text { de cimento }\end{array}$ & $\begin{array}{c}\text { Terreiro lama } \\
\text { asfáltica }\end{array}$ & $\begin{array}{c}\text { Terreiro de } \\
\text { terra }\end{array}$ & $\begin{array}{c}\text { Terreiro leito } \\
\text { suspenso }\end{array}$ \\
\hline C.D. ${ }^{1}$ & $122,10 \mathrm{~A} \mathrm{a}$ & $126,03 \mathrm{~A} \mathrm{ab}$ & $231,87 \mathrm{~B} \mathrm{~d}$ & $153,04 \mathrm{~A} \mathrm{bc}$ & $174,70 \mathrm{~A} \mathrm{C}$ \\
Boia & $224,70 \mathrm{C} \mathrm{a}$ & $217,53 \mathrm{~B} \mathrm{a}$ & $301,85 \mathrm{C} \mathrm{C}$ & $243,28 \mathrm{C} \mathrm{ab}$ & $270,36 \mathrm{~B} \mathrm{~b}$ \\
Roça & $199,42 \mathrm{~B} \mathrm{a}$ & $249,25 \mathrm{C} \mathrm{b}$ & $183,07 \mathrm{~A} \mathrm{a}$ & $201,44 \mathrm{~B} \mathrm{a}$ & $185,83 \mathrm{~A} \mathrm{a}$ \\
\hline
\end{tabular}

Médias seguidas pelas mesmas letras maiúsculas na coluna (tipo de terreiro) e minúsculas na linha (tipo de processamento), não diferem entre si pelo teste de tukey a $5 \%$ de probabilidade. ${ }^{1}$ C.D.: cereja descascado Fonte: Santos, O. L. (2014)

Na tabela 2 podemos observar que houve diferença estatística entre os processamentos de café e entre os terreiros.

Verifica-se que, estatisticamente a um nível de $5 \%$ de probabilidade, foram encontrados menores valores de condutividade elétrica nos cafés secados em terreiro de concreto e lama de cimento. Os maiores valores de condutividade elétrica foram detectados nos cafés secados em terreiro de lama asfáltica; Reinato (2006) também observou esse mesmo comportamento para os cafés secados em terreiro de concreto e lama asfáltica. Ressalta-se que os valores numéricos de condutividade elétrica encontrados neste teste estão dentro dos valores médios obtidos em trabalhos de vários autores (CARVALHO, 1985; CHAGAS, 1994; CARVALHO et al, 1994; REINATO et al 2005; REINATO, 2006). 
Segundo Reinato (2006), o teste de condutividade elétrica tem se mostrado como um indicador consistente da integridade da membrana. Maiores valores e aumentos da condutividade elétrica ocorrem em função da degradação das membranas ocasionadas por possíveis fatores, tais como: temperatura elevada, deterioração e fermentação durante o processo de secagem. Neste contexto provavelmente a ocorrência de maiores valores de condutividade elétrica no terreiro de lama asfáltica está relacionada a picos de temperaturas maiores obtidos neste tipo de terreiro.

Em relação aos tipos de processamentos, de maneira geral, os menores valores de condutividade elétrica foram encontrados nos cafés cereja descascado, seguido pelo roça e boia, indo ao encontro dos resultados obtidos por Reinato et al. 2005, isso pode ser explicado pela maior exposição dos cafés tipo boia às intempéries e consequentemente ao ataque de micro-organismos ocasionados quando eles ainda estão na planta mãe.

Tabela 3. Classificação pela prova de xícara, com avaliação de três provadores do café arábica, submetido a cinco tipos diferentes de secagem. Machado, 2014, IFSULDEMINAS Campus Machado.

\begin{tabular}{lccccc}
\hline $\begin{array}{c}\text { Tipo de } \\
\text { processamento }\end{array}$ & $\begin{array}{c}\text { Terreiro de } \\
\text { concreto }\end{array}$ & $\begin{array}{c}\text { Terreiro lama de } \\
\text { cimento }\end{array}$ & $\begin{array}{c}\text { Terreiro lama } \\
\text { asfáltica }\end{array}$ & Terreiro de terra & $\begin{array}{c}\text { Terreiro leito } \\
\text { suspenso }\end{array}$ \\
\hline Cereja & Duro & Duro & Riado & Riado & Duro \\
Descascado & Duro & Duro & Riado & Riado & Duro \\
& Riado & Riado & Riado & Rio & Riado \\
\hline \multirow{3}{*}{ Boia } & Duro & Riado & Riado & Riado & Duro \\
& Riado & Riado & Riado & Riado & Riado \\
& Duro & Duro & Rio & Rio & Duro \\
\hline \multirow{2}{*}{ Roça } & Riado & Duro & Rio & Rio & Riado \\
& Duro & Riado & Rio & Rio & Duro \\
& Duro & Duro & Rio & Rio & Duro \\
\hline
\end{tabular}

Fonte: Elaboração dos autores

Na Tabela 3 observa-se que, de acordo com a análise sensorial, os terreiros de lama asfáltica e terra apresentaram em média bebidas rio e riado. Os terreiros de concreto, lama de cimento e suspenso apresentaram, na sua maioria, bebida do tipo duro.

Observa-se com os resultados acima que o terreiro de lama de cimento mostrou-se uma ótima opção para substituir o terreiro de terra, tanto do ponto de vista econômico quanto do ponto de vista da qualidade.

\section{Conclusão}

Após análise dos resultados, pode-se tirar as seguintes conclusões:

O terreiro de lama de cimento se mostrou uma ótima opção do ponto de vista econômico para substituição do terreiro de terra.

Observou-se que o terreiro de lama de cimento interferiu de maneira similar e positiva na qualidade final do café.

\section{Agradecimentos}

Ao IFSULDEMINAS - Campus Machado pelo apoio técnico, financeiro e concessão da área, ao professor-orientador e aos colaboradores. 


\title{
Cost-benefit comparison of coffee drying in different types of yards
}

\begin{abstract}
The subject of this investigation was to compare the cost between building a yard of mud cement and other types of coffee drying yards, as well as to check how these types of yards change the coffee physical, chemical and sensory quality. The experiment consisted of a fully, randomized design (DIC) with treatments in factorial scheme. It was used three replications. After drying, the experimental units were processed and submitted to analysis. To evaluate the chemical and physical composition, an electrical conductivity analysis was performed, and a sensory analysis was performed to assess quality. The results showed that the mud cement yard presents itself as an excellent economic and qualitative alternative for drying coffee.
\end{abstract}

Keywords: Post-harvest. Paving. Influence. Processing. Coffee cultivation.

\section{Referências}

BARTHOLO, G. F.; GUIMARÃES, P. T. G. Cuidados na colheita e preparo do café. Informe Agropecuário, V. 18, n. 187, p. 33-42, 1997.

BEDFORD, L. V. Conductivity tests in commercial and hand harvested seed of pea cultivars and their relation to field establishment. Seed Science and Technology, Zurich, v. 2, n. 3, p. 323-335, 1974.

BORÉM, F. M.; REINATO, C. H. R.; ANDRADE, E. T. Secagem do café.In: BORÉM, F. M. (Ed.). Pós-colheita do café. Lavras: UFLA, 2008. p. 205-240

BORÉM, F. M.; REINATO, C. H. R.; PEREIRA, R. G. F. A. Alterações na bebida do café despolpado secado em terreiro de concreto, lama asfáltica, terra, leito suspenso e em secadores rotativos. In: SIMPÓSIO DE PESQUISA DOS CAFÉS DO BRASIL, 3, 2003, Porto Seguro, BA, Anais... Porto Seguro, 2003. p. 155.

BRANDO, C. H. J. Cereja descascado, desmucilado, fermentado, despolpado ou lavado? In: CONGRESSO BRASILEIRO DE PESQUISAS CAFEEIRAS, 25., 1999, Franca. Anais... Rio de Janeiro: MAA/PROCAFÉ, 1999. p. 342-346

BRASIL. Ministério da Agricultura, Pecuária e Abastecimento. Instrução Normativa $\mathbf{n}^{\circ} \mathbf{8}$, de 11 de Junho de 2003. Aprova o regulamento técnico da identidade e de qualidade para a do café beneficiado grão cru. Brasília, 2003. Disponível em: <http://www.abic.com.br/publique/media/NMQ_LEGISLAcaO_IN8.pdf>. Acesso em: 05 out. 2015.

CAMARGO, R. A. L. de; OLIVEIRA, J. T. A. de. Economical and cultural constraints in the adoption of agroecological methods: a case study in Minas Gerais - Brazil. ISDA 2010, Montpellier, p. 28 - 30, 2010. FREUND, J. E.; SIMON, G. A. Estatística aplicada: economia, administração e contabilidade. 9. ed. Porto Alegre: Bookman, 2000. 404 p.

CARVALHO, V. D. de; CHAGAS, S. J. de R.; CHALFOUN, S. M.; BOTREL, N.; JUSTE JUNIOR, E. S. G. Relação entre a composição fisico-química e química do grão beneficiado e qualidade de bebida do café. Pesquisa Agropecuária Brasileira, v. 29, n. 3, p. 449-454, 1994. 
CARVALHO, V. D.; CHALFOUN, S. M. Aspectos qualitativos do café. Informe Agropecuário, v. 11, n. 126, p. 79-92, 1985.

CHAGAS, S. J. R. Caracterização química e qualitativa de cafés de alguns municípios de três regiões produtoras de Minas Gerais. 1994. 83f. Dissertação (Mestrado em Ciência dos Alimentos)-Escola Superior de Agricultura de Lavras, Lavras, 1994.

CHAGAS, S. J. R.; MALTA, M. R. Avaliação da composição química do café submetido a diferentes formas de preparo e tipos de terreiros de secagem. Revista Brasileira de Armazenamento, n. 10, p. 1-8, 2008. Edição especial.

CORTEZ, J. G. Efeito de espécies e cultivares e do processamento agrícola e industrial nas características da bebida do café. 1997. 71 f. Tese (Doutorado) - Escola Superior de Agricultura "Luiz de Queiroz", Piracicaba, 1997.

FERREIRA, D. F. SisVar ${ }^{\circledR}$ : Sistema de análise de variância para dados balanceados, versão 4.0. Lavras: DEX/UFLA, 2000. (Software estatístico).

HALL, C. W. Drying and storage of agricultural crops. Connecticut: AVI, 1980. 381 p.

HASHIZUME, H. Estudo comparativo dos principais tipos de terreiro pavimentado para secagem de café. In: CONGRESSO BRASILEIRO DE PESQUISAS CAFEEIRAS, 12., 1985, Caxambu, MG. TrabaIhos apresentados... Rio de Janeiro: IBC, 1985. p. 95-97.

LACERDA FILHO, A. F. Avaliação de diferentes sistemas de secagem e suas influências na qualidade do café (CoffeaarabicaLineu). 1986. 136 f. Dissertação (Mestrado) - Universidade Federal de Viçosa, Viçosa, MG, 1986.

LACERDA FILHO, A. F.; SILVA, J. S.; HARA, T. Avaliação de diferentes sistemas de secagem e suas influências na qualidade de café (Coffeaarabica L.). Acogranos, v. 14, n. 161, p. 23-29, 1989.

MALTA, M. R.; CHAGAS, S. J. R.; OLIVEIRA, W. M. Composição físico-química e qualidade do café submetido a diferentes formas de pré-processamento. Revista Brasileira de Armazenamento, n. 6, p. 37-41, 2003. Especial café.

PRETE, C. E. C. Condutividade elétrica do exsudato de grãos de café (Coffeaarabica L.) e sua relação com a qualidade da bebida. 1992. 125 f. Tese (Doutorado em Fitotecnia) Escola Superior de Agricultura Luiz de Queiroz, Piracicaba, 1992.

PUERDA-QUINTERO, G. I. P. Evalución de la calidade del café colombiano processado por via seca. Cenicafé, v. 47, n. 2, p. 85-90, 1996.

REINATO, C. H. R. Secagem e armazenamento do café: aspectos qualitativos e sanitários. 2006. 111 f. Tese (Doutorado em Ciências dos Alimentos) - Universidade Federal de Lavras, Lavras, 2006.

REINATO, C. H. R.; BORÉM, F. M.; CIRILLO, M. Â.; OLIVEIRA, E. C.; Qualidade do café secado em terreiros com diferentes pavimentações e espessuras de camada. Coffee Science, v. 7, n. 3, p. 223$237,2012$. 
REINATO, C. H. R.; BORÉM, F. M.; SILVA, P.; ABRAHÃO, E. J. Qualidade da bebida dos cafés descascado, cereja, bóia e roça secados em terreiros de terra e lama asfáltica. In: CONGRESSO BRASILEIRO DE PESQUISAS CAFEEIRAS, 31., 2005, Guarapari. Anais... Guarapari, 2005. p. 314- 315.

SANTIAGO, R.; TEIXEIRA, A. Estudos preliminares sobre tipos de terreiro para secagem de café. In: CONGRESSO BRASILEIRO DE PESQUISAS CAFEEIRAS, 1977, Guarapari, ES. Resumos... Rio de Janeiro: IBC/GERCA, 1977. p. 257-259.

SANTOS, A. C. dos; MATOS, N.; LIMA, A. R.; FONSECA, R.; CORREIA, C.; MEXIA, J. T. Estudo preliminar de terreiros para secagem de café. Colloque Scientifique International Sur le Café, 5. , Lisbonne (Portugal), Juin 14-19, 1971. Paris, ASIC, p. 235- 245.

SILVA, C. G. da; CORRÊA, P. C.; MARTINS, J. H. Qualidade da bebida do café (Coffeaarabica L.) em função da proporção de frutos verdes e da temperatura do ar de secagem. Revista Brasileira de Armazenamento, v. 23, n. 1, 45-48, 1998.

SILVA, O. F.; COSTA, R. A.; FARIAS, A. X.; SOUZA, M. L.; CORRÊA, T. B. S.; FRAGA, M. E. Avaliação da composição química do café submetido a diferentes formas de preparo e tipos de terreiro de secagem. Revista Brasileira de Armazenamento, v. 1, n. 10, p. 1-8, 2008.

SIQUEIRA, Tagore Villarim de. A cultura do café: 1961-2005. BNDES Setorial, Rio de Janeiro, n. 22, p. 205-270, set. 2005.

VIANA, A. S.; MATIELLO, J. B.; SOUZA, T. Estudo do efeito de revestimento de terreiros no tempo de seca e na qualidade do café. In: CONGRESSO BRASILEIRO DE PESQUISAS CAFEEIRAS, 28. Anais... Caxambu, 2002, p. $53-56$.

VILELA, R. V. Qualidade do café; secagem e qualidade do café. Informe Agropecuário, v. 18, n. 187, p. 55-63. 1997.

VILLELA, T. C. Qualidade de café despolpado, desmucilado, descascado e natural, durante o processo de secagem. 2002. 66 f. Dissertação (Mestrado em Ciência dos Alimentos) - Universidade Federal de Lavras, Lavras MG, 2002.

WILBAUX, R. Agricultural engineering. Rome: FAO,1963.

WOODSTOCK, L. W. Physiological and biochemical tests for seed vigor. Seed Science and Technology, Zurich, v. 1, n. 1, p. 127-157, 1973.

\section{Histórico editorial:}

Submetido em: 15/03/2016

Aceito em: 09/09/2016 
Como citar:

ABNT

SANTOS, O. L.; REINATO, C. H. R.; JUNQUEIRA, J. D.; FRANCO, E. L.; SOUZA, C. W. A.; REZENDE, A. N. Custo-benefício da secagem de café em diferentes tipos de terreiro. Revista Agrogeoambiental, Pouso Alegre, v. 9, n. 4, p. 11-21, out./dez. Doi: http://dx.doi.org/10.18406/2316-1817v9n42017966

$\underline{A P A}$

SANTOS, O. L., REINATO, C. H. R., JUNQUEIRA, J. D., FRANCO, E. L., SOUZA, C. W. A. \& REZENDE, A. N. (2017). Custo-benefício da secagem de café em diferentes tipos de terreiro. Revista Agrogeoambiental, 9 (4), 11-21. Doi: http://dx.doi.org/10.18406/2316-1817v9n42017966

\section{$\underline{\text { ISO }}$}

SANTOS, O. L.; REINATO, C. H. R.; JUNQUEIRA, J. D.; FRANCO, E. L.; SOUZA, C. W. A. e REZENDE, A. N. Custo-benefício da secagem de café em diferentes tipos de terreiro. Revista Agrogeoambiental, 2017, vol. 9, n. 4, pp. 11-21. Eissn 2316-1817. Doi: http://dx.doi.org/10.18406/2316-1817v9n42017966

\section{VANCOUVER}

Santos OL, Reinato CHR, Junqueira JD, Franco EL, Souza CWA, Rezende AN. Custo-benefício da secagem de café em diferentes tipos de terreiro. Rev agrogeoambiental. 2017 out/dez; 9(4): 11-21.

Doi: http://dx.doi.org/10.18406/2316-1817v9n42017966 